\title{
A SURVEY OF \\ PARENT TRAINING MANUALS
}

\author{
Martha E. Bernal and Juel ANN NORTh ${ }^{1}$
}

\author{
UNIVERSITY OF DENVER AND NATIONAL ASTHMA CENTER, DENVER, COLORADO
}

\begin{abstract}
Twenty-six commercially available parent training manuals were surveyed with the goal of providing helpful information to the professional for selection of manuals. Included were manuals for parents as well as manuals for professionals for use in conducting individual or group treatment. The following information was given for all manuals: the characteristics of the target populations for whom the manuals were intended, readability levels, use made of technical language, provision of glossary, organization and format of the book, availability of supplementary materials such as leaders' guides, and references to reviews by other authors. In an additional section, the research literature dealing with evaluation of these manuals was reviewed and summarized as a means of acquainting the reader with the available scientific information on their effectiveness. A report on the status of each manual in terms of evaluation was provided in tabular form. The evaluation of manuals by conduct of empirical research to determine their usefulness to the consumer was emphasized.
\end{abstract}

KEY WORDS: training manuals, parents, children

The trend toward the increasing use of parents as change agents for their children was given impetus by personpower shortages in the mental health field, revised service delivery approaches, and the new uses of nonprofessionals and paraprofessionals (Reisinger, Ora, and Frangia, 1976). In particular, behavioral approaches to child treatment have emphasized the need to train social agents, especially parents, in the child's natural environment in order to bring about durable, generalized changes in children. As a consequence of these developments, there has been a surge of efforts to develop treatment technologies that make the treatment procedures needed operational. These efforts have resulted from an awareness of the paucity of materials for training parents or for communicating the information necessary for parents to become effective change agents.

Since publication of Patterson and Gullion's original version of Living with Children in 1968, manuals for parents and for professionals who train parents have been produced at an increasing rate by behaviorally oriented authors seeking to meet the needs of the growing number of con- sumers of these materials. Some of the publications have been aimed at parents in general, while others have been intended for use as reading material for parents seeking professional guidance. Some manuals focus on normal children, whereas many of them have as their targets children with varying behavioral and developmental problems. Topics of the manuals range from general rearing of children to teaching of specific skills such as toileting. A more recent development is the publication of manuals for professionals and paraprofessionals to train parents to help their own problem children. These manuals usually provide extensive descriptions of procedures for systematic assessment of parent-child interactions and for intervention, emphasizing the applied technology of parent training. Some manuals describe methods for

${ }^{1}$ This work was supported in part by Grant No. MH20922 from the National Institute of Mental Health to the senior author. We express our special appreciation to Terrie Wasson for typing this manuscript and to Mary D. Klinnert for her thoughtful suggestions. Reprints may be obtained from Martha E. Bernal, University of Denver, Department of Psychology, 2030 South York, Denver, Colorado 80210. 
training parents in groups, while others emphasize an individual family oriented clinical approach. Case illustrations and data graphs demonstrating the effects of given procedures in clinical experience are included, although some manuals are much more data-oriented than others.

In the present paper, an attempt has been made to collect these parent training publications, organize them, and present information that may be useful to the professional in selecting a book to recommend to parents or for the professional to use as a manual for conducting individual or group treatment. Twenty-six commercially available manuals have been reviewed. The list of manuals was generated by writing to publishers and asking for copies of books on this topic, by suggestions from colleagues, and from articles in behavior modification journals.

The information is presented in Table 1. All books are ordered alphabetically under two major headings; books for parents and books for professionals. The number of pages, cost of the book (paperback, if available), and information on translations are given in the first column.

\section{TARGET POPULATION}

In Table 1, the second column identifies the age grouping of the target population for whom the manual is intended. When a book is intended for the entire family, it has been so identified. Manuals for professional leaders of parent groups are marked by footnote.

Column 3 describes the characteristics of the population for which the book is intended, when they have been identified by the author. More commonly, manuals are intended for use with normal children who present general childrearing problems; the term "general" identifies these manuals.

\section{MANUAL CHARACTERISTICS}

The levels of readability of the printed material calculated according to Flesch's Reading
Ease Formula (Flesch, 1948, 1949) ${ }^{2}$ follow in column 4. Columns 5 and 6 are used to indicate by an " $\mathrm{X}$ " whether or not any technical language (operant, social learning, or behavioral terms) has been used in the manual and whether a glossary of terms is provided. In column 7 , it is indicated whether the book is programmed, i.e., the material provides the reader feedback on comprehension of material through use of periodic opportunities to test and self-score knowledge. References are given in column 8 for any supplementary materials, manuals, or packages available. These materials may consist of assessment forms, trainer guides, program director manuals, and various printed and audiovisual materials that are not included in the manual package.

In terms of organization and content of the material, all except two books present behavioral principles and their application in a well organized fashion and use technical language accurately when it is used. The present authors' impressions about these two exceptions have been corroborated by other reviewers. Krumboltz and Krumboltz (1972) contains various personal opinions, generalizations which are unjustified, confusion in technical terminology, and chapter titles that fail to reflect chapter content (Berger, 1973; O'Leary, 1972). The writing in Tymchuk (1974) does not flow well, and tech-

${ }^{2}$ The Flesch Reading Ease formula (Flesch, 1948, 1949) was used to estimate reading level by grade of all books. For 10 of the books, Flesch readability levels provided by Andrasik and Murphy (1977) were used; these books may be identified by an asterisk which follows the readability level. Readability levels for the remaining books were estimated by the authors as recommended by Andrasik and Murphy (1977). Flesch's Reading Ease Score is determined by computing average sentence length and syllable count for selected passages from the text. In our case, we obtained 20 such passage samples from each text. The obtained numerical values are inserted into Flesch's Reading Ease formula yielding a score ranging from 0 , practically unreadable, to 100 , easy for any literate person. The 100 scale points are grouped into seven difficulty categories, each with a corresponding reading level, from college graduate to fifth grade. Two independent scorers computed readability levels on seven manuals and obtained $87 \%$ agreement. 


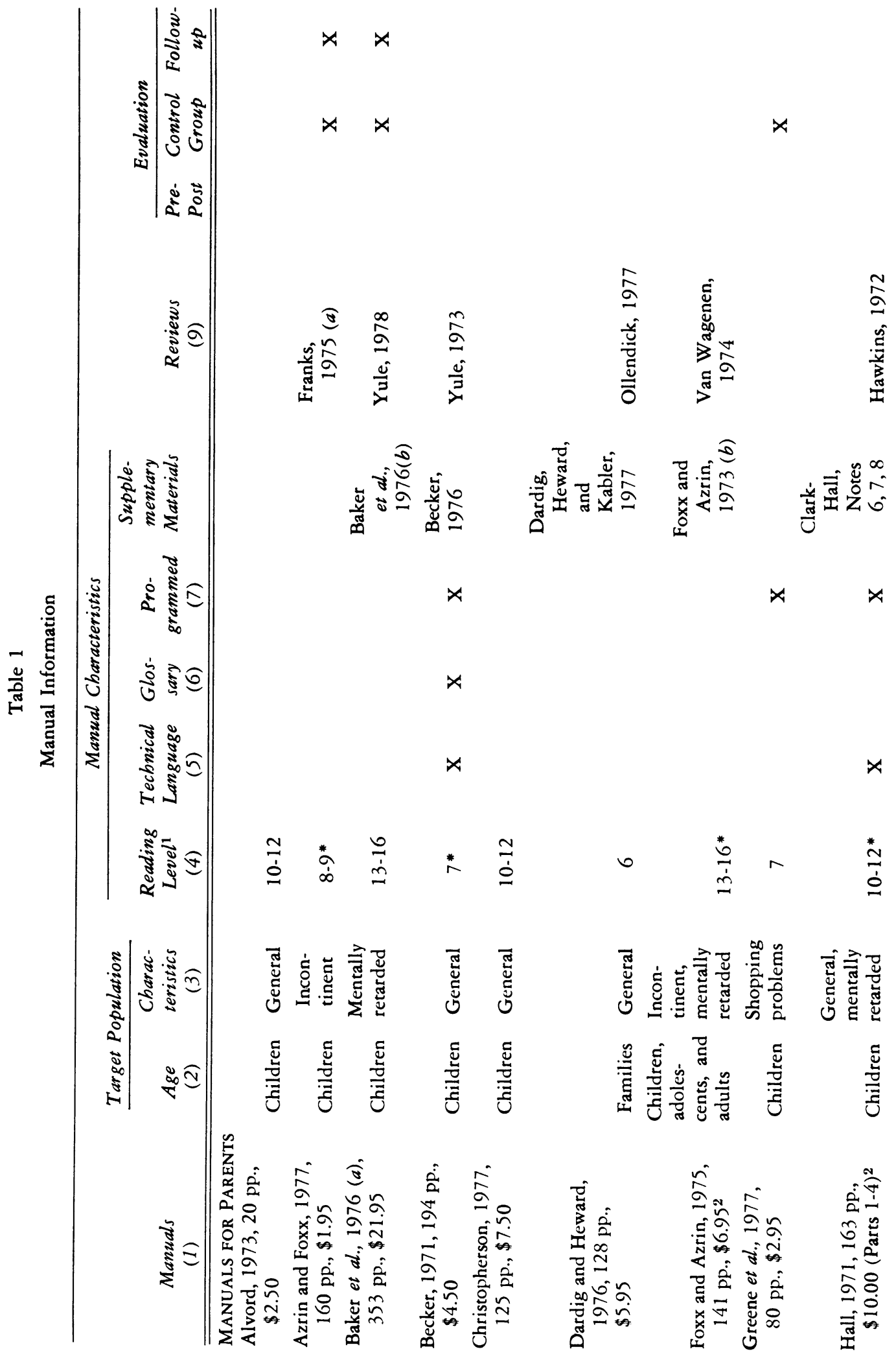




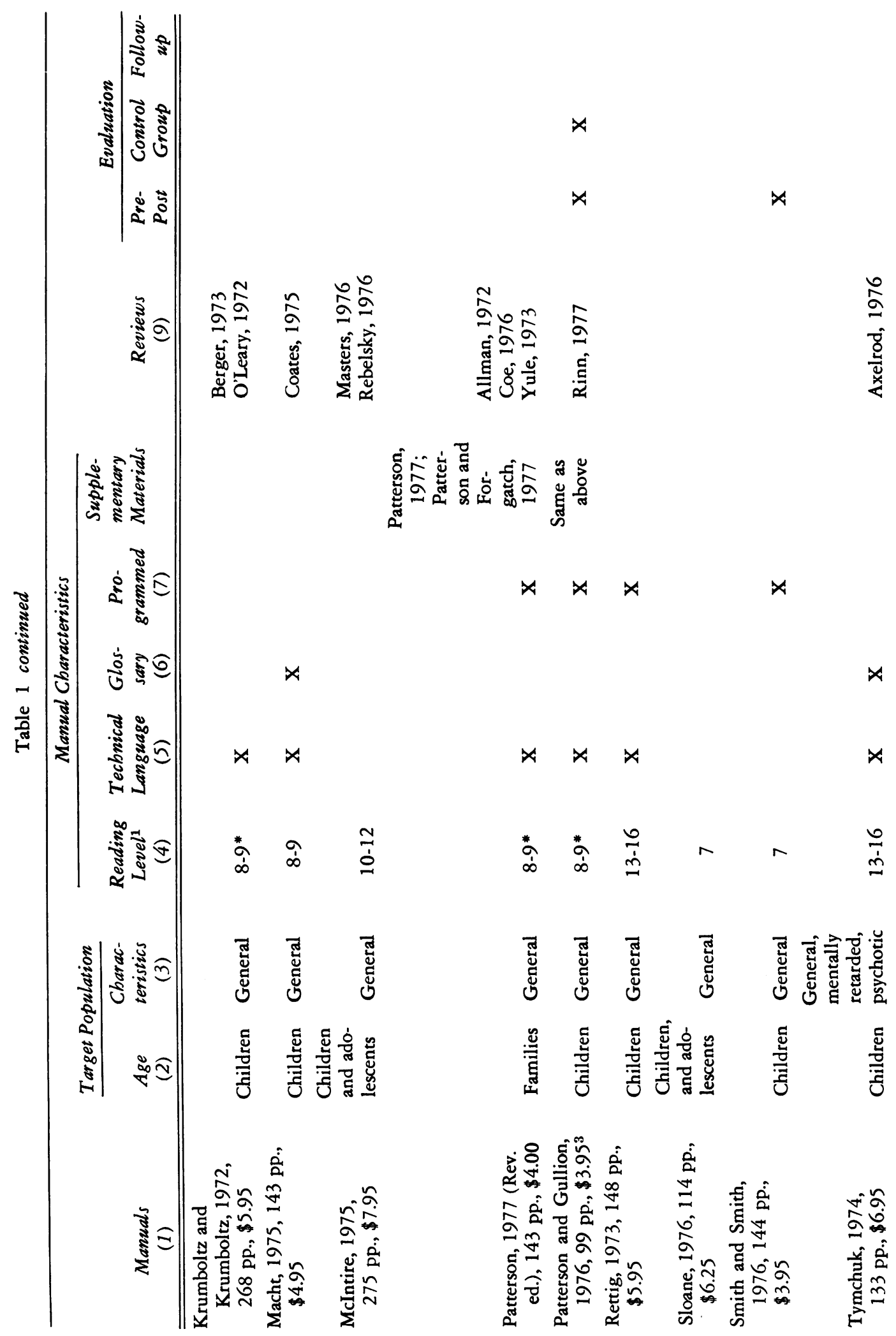




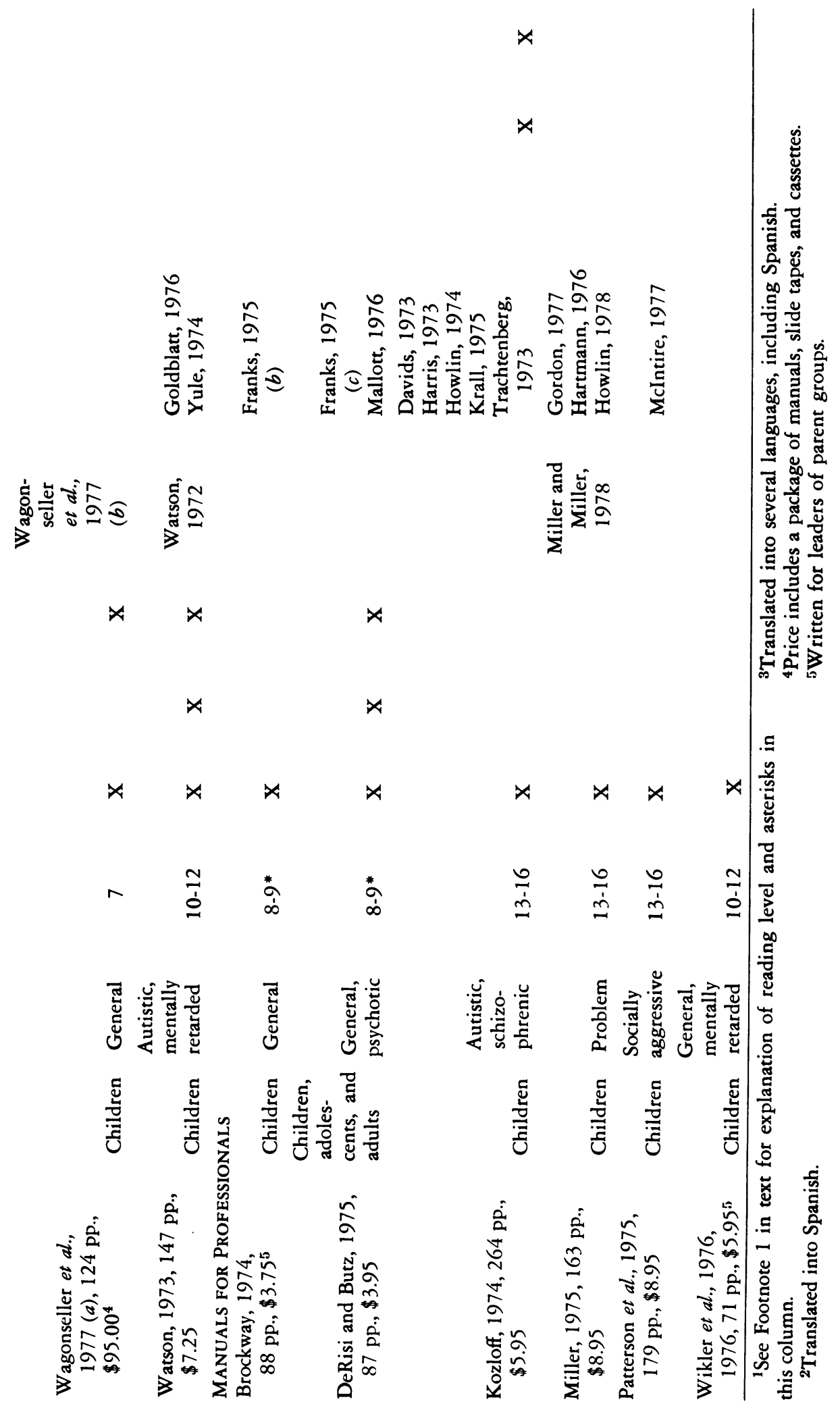


nical terms are used inaccurately before definitions are provided (Axelrod, 1976).

The issue of whether to critique and compare the manuals was one which the present authors considered seriously. On the one hand, it seemed possible that readers could benefit from discussion of the strengths and weaknesses as well as special features of each book. On the other hand, the authors reasoned that such discussion would be purely subjective and perhaps even unfair, because they made no systematic effort to use and evaluate each one. Therefore, it was decided that little of value could be added by such critiques and, instead, a search of the literature was made for published reviews. This search yielded at least one review by experts in the field for all except three of the listed manuals. These reviews are referenced in column 9.

\section{EVALUATION}

The right-hand section in the table represents an assessment of the current state of the science of parent training manuals in terms of evaluation data available. Those manuals that have been formally evaluated in pre-post, control group, and followup studies are identified here. As the reader will note, and as reviewers also have noted (Glasgow and Rosen, 1978; Masters, 1976; Ollendick, 1977; Yule, 1977), few attempts have been made to evaluate the utility of these manuals. A review of these few attempts, and of related research by investigators other than the manuals' authors, is provided below. However, some preliminary comments relative to evaluation are in order.

In reading the manuals and in communicating with several authors who were reached to inquire about evaluation information, it was found that many of them had, by various means, solicited consumer feedback (e.g., Dardig and Heward, 1976; Foxx and Azrin, 1975; Hall, 1971; Sloane, 1976; Wagonsellar, Burnett, Salzberg, and Burnett, 1977a). The present authors suggest that such evaluation is insufficient and lacks experimental rigor and that the only way to determine the usefulness of a manual is to provide direct evidence of its efficacy. A representative sample of naive parent or parent trainer consumers should read the book and apply it, without any other assistance or instruction, and their performance should be evaluated. As a self-contained set of procedures, the manual comprises the independent variable. The dependent variable should be various objective measures of change in both parent and child in the case of manuals for parents; and in professional, parent, and child in the case of manuals for professionals. These measures could reflect changes in parents' or professionals' knowledge and application of principles, confidence in their use, amount of record-keeping in which they engaged attitudes of parents toward their children, etc. Children's skills and appropriate behavior changes expected as a result of their parents' reading of the book also could be measured. Results should provide information on the characteristics of parents and children who will benefit, and those for whom professional assistance will be necessary.

The most basic evaluation design would be to collect measures on a group of consumers before and after they read the book. A more convincing test would be to obtain pre-post measures on more than just one group in order to rule out alternative explanations for change. Random assignment of subjects to appropriate no treatment groups that control for maturation and historical variables, such as visits from relatives, deaths in a family, etc., which might account for change would be necessary. Campbell and Stanley (1963) is highly recommended to the reader interested in discussion of evaluation designs. Because this book is written specifically for application to the assessment of educational practices in natural settings, it provides valuable guidance to the professional engaged in evaluating parent training manuals in clinics and schools.

To determine what gains might be obtained by using the manual along with other training experiences, two other types of groups can be 
added. The first type is a minimal contact group that gets professional consultation (e.g., via telephone) but for which the primary training experience is reading the manual. The second type is a therapist-administered program group where clients attend regular meetings with the therapist for the purpose of elaborating the manual's contents (Glasgow and Rosen, 1978). Glasgow and Rosen (1978) also advocate the use of a therapist-directed group to evaluate effects of contact with a therapist when a manual is not used, or of a placebo treatment group to evaluate nonspecific effects of treatment such as expectation of change and therapist contact.

Followup evaluation of the extent to which changes are maintained over time would be highly desirable. And, finally, it is useful to determine what set of training experiences best assure that parents generalize their skills to new child behaviors and settings.

Certain manuals lend themselves better to testing than others. Manuals that are designed for specific purposes can be evaluated most readily because they spell out procedures for given observable tasks for which measures of expected change can be more easily developed. For example, Dardig and Heward (1976), DeRisi and Butz (1975), Greene, Clarke, and Risley (1977), and Sloane (1976) are designed to teach specific sets of skills, while Macht (1975) or Miller (1975) would be much less focussed on given skills and more on a broad repertoire. Consequently, evaluation measures would be more difficult to develop for the latter. Nevertheless, both paper and pencil tests as well as performance tests of conceptual understanding and clinical application could be developed for these manuals.

\section{REVIEW OF EVALUATION RESEARCH}

Azrin and Foxx (1977) and Foxx and Azrin (1975) have provided excellent examples of manuals designed specifically for imparting a given set of parenting skills-toilet training. The success of parents who read the manual can be directly measured by counting the number of child toileting accidents over time. Foxx and Azrin (1973a) presented data on the toilet training of 34 normal children whose mean age was 25 months. All children were successfully trained in an average time of four hours. Parents were excluded from the training, however, so this evaluation was not a test of the effectiveness of a manual, but rather of experienced trainers using procedures described in the manual. Butler (1976) has evaluated the effectiveness of parents in toilet training their own normal children using the Azrin and Foxx (1977) book and a therapist-directed format involving lectures and discussion. This program resulted in the successful training of 49 children in an average time of 4 $\frac{1}{2}$ hours. The only test of Azrin and Foxx (1977) which has separated the book and therapist-administered variables has been provided by Matson and Ollendick (1977). These investigators randomly assigned mothers of 10 normal children ages 20 to 26 mo to Book Alone and Training plus Book groups, and followed them up for nine weeks. Results of this study showed that parents who self-administered had poor success compared to parents who were supervised and read the manual. Only one out of five Book Alone mothers trained her child, while four out of five Training plus Book mothers succeeded. Mothers who were unsuccessful in training their children in the Book Alone group experienced bewilderment and frustration when their children developed emotional side effects as a result of application of some procedures. Given the vast benefits that a manual for toilet training can offer parents, it seems highly desirable that additional empirical research be conducted to isolate and modify the offending procedures so that these modifications can be included in future manual revision. Furthermore, because the manual has wide appeal to all parents when their children are developmentally capable of being toilet trained, it seems important that the manual be assessed for its applicability to broader populations of children.

The most exemplary case of evaluation of a complex manual for parents dealing with a large 
number of child-rearing tasks is Baker, Brightman, Heifetz, and Murphy (1976a). This manual presents highly specific programs for teaching self-help skills which can easily be assessed. In Baker and Heifetz (1976), parents of 160 retarded children ages 3 to $14 \mathrm{yr}$, were randomly assigned to five conditions: (1) a Control group that received no training or reading during a four-month period, (2) a Manual Only group that was provided manuals for reading but otherwise had no staff contact, (3) a Manual and Phone Consultation group that read the manuals and also had bi-weekly scheduled phone calls, (4) a Manual and Group Training group that read the manuals and participated in an 18-hour training program, and (5) a Manual plus Group Training plus Home Visit group that, in addition to manuals and group training, also involved staff making six one-hour home visits to each family. Measures were taken of parent participation and knowledge of behavior modification as well as child self-help skills and behavior problems. For self-help skills, the staff contact conditions resulted in more record keeping and more areas programmed by parents; however, the mothers using the manuals alone showed the greater gain in knowledge of behavior modification, while father knowledge increased most with staff contact. For behavior problems, the results were different: the staff contact conditions generally were superior. The authors suggested that this superiority might have resulted because handling child behavior problems involves the application of general principles to the individual case, which probably is more difficult than applying a specific program to train a specific skill. A followup study (Baker and Heifetz, Note 1) evaluated persistence of both parent and child behavior changes 14 months after training with the finding that professionally supported treatment groups were doing better than the manual alone parents in teaching their children new behaviors.

Using a therapist administered format, Shrewsberry (Note 2) and Norman (Note 3) were successful in teaching contingency con- tracting to groups of mothers in a six-week training program using the procedures described and illustrated in Dardig and Heward (1976). Unfortunately, no self-administered or manual alone group was included.

Greene, Clark, and Risley (1977) focussed on a discrete set of child skills, courteous shopping, occurring in a given setting, a store, or supermarket. The manual was written according to a model advocated by Risley, Clark, and Cataldo (1976). Extensive interviewing of families was done to isolate common child problems, and observation of the families determined the procedures for solving the particular shopping problem. The procedures contained in the manual have been tested, revised, and retested with naive families in in vivo situations. A report of the effectiveness of the advice package by Clark, Greene, Macrae, McNees, Davis, and Risley (1977), provides systematic observation data on 12 families during shopping trips. The data demonstrate that mothers can use the written advice package successfully without therapist assistance.

Kozloff's book (1974) is not a manual in that it does not attempt to instruct the reader. Rather, it is a research report of his extensive work with parents of autistic children, and it contains clear detailed description of the independent variable, parent training. This description qualifies it for inclusion in this paper. A broad approach to autism was taken in which the author dealt with eye contact, language, and constructive and disruptive behaviors in autistic children by applying multiple procedures. Measures were taken on both the parents and the children in laboratory and home settings before, during, and after training. The elegant evaluation scheme consisted of an ABCAC design for each of four families. At baseline $A$, data were collected; at $B$, the parents were trained in the laboratory; at $C$, they were observed for generalization into the home and coached in the training procedures. Experimental reversal of the parents' therapeutic behaviors was conducted such that intrasubject replications provided demonstrations of the effects of the train- 
ing on the children. The training program was successful in training parents to be teachers of socially acceptable behaviors, speech, play, performance of chores, and cooperation. Marked beneficial changes also occurred in the behavior of the children. Followup observations at one month for two of the children and 10 months for another child revealed maintenance of trained parent and child behaviors.

Patterson and Gullion (1976) was written for the purpose of imparting conceptual information and a common vocabulary to parents of socially aggressive children who were in treatment. It is used widely as a supplementary text in parent training groups. Patterson and Reid (1973) conducted a pre-post evaluation of the book on a sample of 11 children and reported a modest mean drop of .122 responses per minute of observed deviant child behavior.

Assessment of the effects of a self-instructed group that read Patterson and Gullion (1976) as compared with a group and individually administered family therapy was conducted by Christensen (Note 4). The subject families had at least one child aged 4 to 12 years who displayed behavior problems. Group treatment and individual treatment were found to be more effective than self-instruction on behavioral measures collected via home audiorecordings. However, parental perceptions of improvement in their children showed that all three groups did equally well.

Patterson (1977) is a more sophisticated, comprehensive book that also is widely used, but there is no information about its efficacy. However, intervention procedures described in both these books have been developed and tested empirically in the course of programmatic parent training research. In their manual for professionals, Patterson, Reid, Jones, and Conger (1975) describe these assessment and intervention procedures. The authors point out two important considerations: first, that the procedures are least beneficial for poor families and single parents, as Coe (1976) has suggested; and second, that without supervision the reading of the manual alone will not result in the training of an effective clinician. This type of information regarding the type and extent of training prerequisite to the effective use of manuals is important, particularly for the professional, but few authors (e.g., Brockway, 1974; Miller, 1975) supply it. Patterson and his group currently are evaluating a package for training professionals which incorporates this manual in addition to a variety of training experiences (Reid and Patterson, Note 5).

Smith and Smith (1976) provided pre-post self-examination and self-report data that demonstrated improvement in the parents' knowledge of management principles following reading of their book. No control groups were used, and objective data were not collected.

\section{CONCLUDING REMARKS}

The research literature that has been reviewed suggests that, in selecting a training manual, the professional will wish to keep in mind that the more circumscribed the child's problem the more likely it is that a manual for parents will be useful. By circumscribed is meant that the problem should be very specific and confined to a given time and place. If the manual is written for the purpose of assisting the parent to deal with such a problem, the parent is likely to succeed with little or no professional assistance (e.g. Greene et al., 1977). As children's problems become more diffuse, complex, multiple, and generalized across settings, more professional guidance will be needed. Otherwise, side effects associated with struggles between parents and child and less than satisfactory progress, or failure, may result. Very little data are available on the effectiveness of the few manuals intended for professionals training parents, although almost all of these manuals contain case illustrations with data documenting the effectiveness of given procedures with given children. What is needed, however, is evidence that the manual improved the clinical functioning of the professional. 
The previous training of the professional will be a critical factor in determining the usefulness of a manual. Although there are no empirical investigations of the relationship between previous training of the clinician and success in application of procedures described in a manual, it seems imperative that the professional be thoroughly grounded and trained under expert supervision in use of behavioral techniques with children. The type of practical training experience and background described in Gelfand and Hartmann (1975), plus a solid education in basic behavioral principles and procedures is recommended as a prerequisite to the use of these manuals.

In addition to the information provided in Table 1, the reader may wish to read the reviews of the manual. These reviews sometimes offer opposing viewpoints, but nevertheless they are helpful in making a decision about use of a manual. The most crucial information, however, is whether there is any evidence at all that the manual will work. The dearth of manual evaluation efforts fails to reflect the scientific training of the behavior therapists who wrote them. Evaluation developments described here hopefully will provide incentive and models for future assessment of manuals.

\section{REFERENCE NOTES}

1. Baker, B. L., and Heifetz, L. J. Manpower and metbodology in bebavior modification: Parents as teachers one year after training. Paper presented at the meeting of the Association for Advancement of Behavior Therapy, San Francisco, December 1975 .

2. Shrewsberry, R. D. Assignment completion in group parent training. Unpublished doctoral dissertation, The Ohio State University, 1977.

3. Norman, J. The effects of programmed instruc. tional material for parent training and contingency contracting. Unpublished doctoral dissertation, The Ohio State University, 1977.

4. Christensen, A. Cost effectiveness in behavioral family therapy. Unpublished doctoral dissertation, University of Oregon, 1976.

5. Reid, J. B., and Patterson, G. R. Personal communication. July 1977.

6. Clark-Hall, M. Group leader manual for the re- sponsive parenting program, rev. ed. Unpublished copyrighted manuscript, 1977. (a)

7. Clark-Hall, M. Parent manual for the responsive parenting program, rev. ed. Unpublished copyrighted manuscript, 1977. (b)

8. Clark-Hall, M. Program director manual for the responsive parenting program, rev. ed. Unpublished copyrighted manuscript, 1977. (c)

\section{REFERENCES}

Allman, L. R. Review of Families: Applications of social learning to family life by G. R. Patterson. Bebavior Therapy, 1972, 3, 497-498.

Alvord, J. R. Home token economy: An incentive program for children and their parents. Cham. paign, Illinois: Research Press, 1973.

Andrasik, F. and Murphy, W. D. Assessing the readability of thirty-nine behavior modification training manuals and primers. Journal of Applied Behavior Analysis, 1977, 2, 2-5.

Axelrod, S. Review of Behavior Modification with children: A clinical training manual by A. J. Tymchuk. Behavior Therapy, 1976, 7, 137-139.

Azrin, N. H. and Fcxx, R. M. Toilet training in less than a day. New York: Simon \& Schuster, 1977.

Baker, B. L., Brightman, A. J., Heifetz, L. J., and Murphy, D. M. Steps to independence series: Early self-belp skills; intermediate self-belp skills; advanced self-belp skills; behavior problems; toilet training. Champaign, Illinois: Research Press, 1976. (a)

Baker, B. L., Brightman, A. J., Heifetz, L. J., and Murphy, D. M. Steps to independence series: Training guide. Champaign, Illinois: Research Press, 1976. (b)

Baker, B. L. and Heifetz, L. J. The Read project: Teaching manuals for parents of retarded. In $\mathrm{T}$. D. Tjossen (Ed), Intervention with bigh risk infants and young children. Baltimore: University Park Press, 1976.

Becker, W. C. Parents are teachers. Champaign, Illinois: Research Press, 1971.

Becker, W. C. Parents are teachers: Group leader guide. Champaign, Illinois: Research Press, 1976

Berger, M. Review of Changing children's behavior by J. D. Krumboltz and H. B. Krumboltz. Behaviour Research and Therapy, 1973, 11, 148 149.

Brockway, B. S. Training in child management: $A$ family approach. Dubuque, Iowa: Kendall/Hunt, 1974.

Butler, J. F. The toilet training success of parents after reading Toilet training in less than a day. Bebavior Therapy, 1976, 7, 185-191.

Campbell, D. T. and Stanley, J. C. Experimental and quasi-experimental designs for research. Chicago: Rand McNalley, 1963.

Christopherson, E. R. Little people: Guidelines for 
common sense rearing. Lawrence, Kansas: $\mathrm{H} \& \mathrm{H}$ Enterprises, 1977.

Clark, H. B., Greene, B. F., Macrae, J. W., McNees, M. P., Davis, J. L., and Risley, T. R. A parent advice package for family shopping trips: development and evaluation. Journal of Applied Behavior Analysis, 1977, 10, 605-624.

Coates, T. J. Review of Teaching our children by J. Macht. Contemporary Psychology, 1975, 20, 754.

Coe, T. D. Review of Families: Applications of social learning to family life by G. R. Patterson. Contemporary Psychology, 1976, 21, 537-538.

Dardig, J. C. and Heward, W. L. Sign bere: $A$ contracting book for children and their parents. Kalamazoo: Behaviordelia, 1976.

Dardig, J. C., Heward, W. L., and Kabler, M. L. Sign bere: $A$ contracting book for children and their parents: Leader's manual. Kalamazoo: Behaviordelia, 1977.

Davids, A. Review of Reaching the autistic child: $A$ parent training program by M. A. Kozloff. Contemporary Psychology, 1973, 18, 497-498.

DeRisi, W. and Butz, G. Writing behavioral contracts: $A$ case simulation practice manual. Champaign, Illinois: Research Press, 1975.

Flesch, R. The new readability yardstick. Journal of Applied Psychology, 1948, 32, 221-233.

Flesch, R. The art of readable writing. New York: Harper \& Brothers, 1949.

Foxx, R. M. and Azrin, N. H. Dry pants: A rapid method of toilet training children. Bebaviour Re. search and Therapy, 1973, 11, 435-442. (a)

Foxx, R. M. and Azrin, N. H. Toilet training the retarded: Program forms. Champaign, Illinois: Research Press, 1973. (b)

Foxx, R. M. and Azrin, N. H. Toilet training the retarded. Champaign, Illinois: Research Press, 1975.

Franks, C. M. Review of Toilet training in less than a day by N. A. Azrin and R. M. Foxx. Behavior Therapy, 1975, 6, 295. (a)

Franks, C. M. Review of Training in child management: A family approach by B. S. Brockway. Bebavior Therapy, 1975, 6, 594. (b)

Franks, C. M. Review of Writing bebavioral contracts: $A$ case simulation practice manual by W. DeRisi and G. Butz. Bebavior Therapy, 1975, 6, 745. (c)

Gelfand, D. M. and Hartmann, D. P. Child behavior analysis and therapy. New York: Pergamon Press, 1975.

Glasgow, R. E. and Rosen, G. M. Behavioral bibliotherapy: A review of self-help behavior therapy manuals. Psychological Bulletin, 1978, 85, 1-23.

Goldblatt, M. Review of Child behavior modification: A manual for teachers, nurses, and parents by L. S. Watson. Experimental Psychiatry, 1976, 7, 204-205.

Gordon, S. B. Review of Systematic parent training: Procedures, cases, and issues by W. H. Miller. Behavior Therapy, 1977, 8, 118-120.
Greene, B. F., Clark, H. B., and Risley, T. R. Shopping with children: Advice for parents. San Rafael, California: Academic Therapy, 1977.

Hall, R. V. Behavior management series (Parts 1-4). Lawrence, Kansas: H \& H Enterprises, 1971.

Harris, S. Review of Reaching the autistic child: $A$ parent training program by M. A. Kozloff. Behavior Therapy, 1973, 4, 720-722.

Hartmann, D. P. Review of Systematic parent training: Procedures, cases, and issues by W. H. Miller. Contemporary Psychology, 1976, 21, 488-489.

Hawkins, R. P. Review of Behavior management series (Parts 1-4) by R. V. Hall. Bebavior Therapy, $1972,3,489-493$.

Howlin, P. Review of Reaching the autistic child: $A$ parent training program by M. A. Kozloff. Behaviour Research and Therapy, 1974, 12, 362363.

Howlin, P. Review of Systematic parent training: Procedures, cases, and issues by W. H. Miller. Bebaviour Research and Therapy, 1978, 16, 64.

Kozloff, M. A. Reaching the autistic child: $A$ parent training program. Champaign, Illinois: Research Press, 1974.

Krall, V. Review of Reaching the autistic child: $A$ parent training program by M. A. Kozloff. American Journal of Orthopsychiatry, 1975, 45, 181 . 182.

Krumboltz, J. D. and Krumboltz, H. B. Changing children's bebavior. New York: Prentice-Hall, 1972.

Macht, J. Teaching our children. New York: Wiley and Sons, 1975.

Malott, R. W. Review of Writing bebavioral contracts: $A$ case simulation practice manual by W. DeRisi and G. Butz. Journal of Behavior Therapy and Experimental Psychiatry, 1976, 7, 103.

Masters, J. C. Review of Child psychology: $A$ behavioral approach to everyday problems by $\mathrm{R}$. W. McIntire. Bebavior Therapy, 1976, 7, 571-573.

Matson, J. L. and Ollendick, T. H. Issues in toilet training normal children. Behavior Therapy, 1977. 8, 549-553.

McIntire, R. W. Child psychology: A behavioral approach to everyday problems. Kalamazoo: $\mathrm{Be}$ haviordelia, 1975.

McIntire, R. M. Review of $A$ social learning approach to family intervention, Vol. 1: Families with aggressive children by G. R. Patterson et al. Bebavior Therapy, 1977, 8, 526-527.

Miller, W. H. Systematic parent training: Procedures, cases, and issues. Champaign, Illinois: Research Press, 1975.

Miller, W. H. and Miller, N. B. Therapist's guidebook. Champaign, Illinois: Research Press, 1978.

O'Leary, S. G. Review of Changing children's behavior by J. D. Krumboltz and H. B. Krumboltz. Behavior Therapy, 1972, 3, 649-652.

Ollendick, T. H. Review of Sign bere: A contracting book for children and their parents by J. C. Dar- 
dig and W. L. Heward. Bebavior Therapy, 1977, 8, $761-762$.

Patterson, G. R. Families: Applications of social learning to family life. Rev. ed.; Champaign, Illinois: Research Press, 1977.

Patterson, G. R. Professional guide for families and living with children. Champaign, Illinois: Research Press, 1977.

Patterson, G. R. and Forgatch, M. Family living series, Parts $I$ and II: Skill-building audio cassettes. Champaign, Illinois: Research Press, 1977.

Patterson, G. R. and Gullion, M. E. Living with children: New metbods for parents and teachers. Rev. ed.; Champaign, Illinois: Research Press, 1976.

Patterson, G. R. and Reid, J. B. Intervention for families of aggressive boys: A replication study. Behaviour Research and Therapy, 1973, 11, 383394.

Patterson, G. R., Reid, J. B., Jones, R. R., and Conger, R. C. A social learning approach to family intervention, Vol. 1: Families uith aggressive children. Eugene, Oregon: Castalia, 1975.

Rebelsky, F. Review of Child psychology: A behavioral approach to everyday problems by $\mathrm{R}$. W. McIntire. Contemporary Psycbology, 1976, 21, 541-542.

Reisinger, J. J., Ora, J. P., and Frangia, G. W. Parents as change agents for their children: A review. Journal of Community Psychology, 1976, 4, 103. 123.

Rettig, E. B. $A B C$ 'S for parents. Van Nuys, California: Associates for Behavior Change, 1973.

Rinn, R. C. Review of Living with children: New metbods for parents and teachers by G. R. Patterson and M. E. Gullion. Behavior Modification, $1977,1,565.567$.

Risley, T. R., Clark, H. B., and Cataldo, M. F. Behavior technology for the normal, middle-class family. In E. J. Mash, L. A. Hamerlynck, and L. C. Handy (eds), Bebavior modification and families. New York: Brunner/Mazel, 1976, 34-60.

Sloane, H. N. Jr. Bebavior guide series: Stop that fighting; Dinner's ready: Not 'til your room's clean; No more wbining; Because I said so. Fountain Valley, California: Telesis, 1976.

Smith, J. M. and Smith D. E. P. Child management: $A$ program for parents and teachers. Champaign, Illinois: Research Press, 1976. (a)
Smith, J. M. and Smith, D. E. P. Child management: A program for parents and teachers: Discussion guide. Champaign, Illinois: Research Press, 1976. (b)

Trachtenberg, W. Review of Reaching the autistic child: A parent training program by M. A. Kozloff. Journal of Behavior Therapy and Experimental Psychiatry, 1973, 4, 414.

Tymchuk, A. J. Bebavior modification with cbildren: A clinical training manual. Springfield, Illinois: Charles C Thomas, 1974.

Van Wagenen, R. K. Review of Toilet training the retarded by R. M. Foxx and N. H. Azrin. Bebav. ior Therapy, 1974, 5, 280-282.

Wagonseller, B. R., Burnett, M., Salzberg, B., and Burnett, J. The art of parenting: Communication; Assertion training; Bebavior management: Motivation; Behavior management: Metbods; Bebavior management: Discipline. Champaign, Illinois: Research Press, 1977. (a)

Wagonseller, B. R., Burnett, M., Salzberg, B., and Burnett, J. The art of parenting: Leader's guide. Champaign, Illinois: Research Press, 1977. (b)

Watson, L. S. Child behavior modification: $A$ manual for teachers, nurses, and parents. New York: Pergamon Press, 1973.

Watson, L. S. How to use behavior modification with mentally retarded and autistic children: $A$ program for administrators, teachers, parents, and nurses. Libertyville, Illinois: Behavior Modification Technology, 1972.

Wikler, L., Savino, A., and Kyle, N. Bebavior modification parent groups: A training manual for professionals. Thorcfare, New Jersey: Charles B. Slazk, 1976.

Yule, W. Review of Child behavior modification: $A$ manual for teachers, nurses, and parents by L. S. Watson. Bebaviour Research and Therapy, 1974, 12,63 .

Yule, W. Reviews of Families: Application of social learning to family life by G. R. Patterson and Parents are teachers by W. C. Becker. Behaviour Research and Therapy, 1973, 11, 359-360.

Yule, W. Review of Steps to independence series by B. L. Baker et al. Behaviour Research and Therapy. 1978, 16, 56 .

Received 15 August 1977.

(Final Acceptance 17 August 1978.) 